\title{
Composição química e atividade antifúngica do óleo essencial das flores de Bauhinia forficata (Link) e suas propriedades na germinação de sementes de Cucurbita maxima
}

\section{(Duchesne)}

Chemical composition and antifungal activity of the essential oil of Bauhinia forficata Flowers (Link) and its properties in the germination of Cucurbita maxima (Duchesne) seeds

Composición química y actividad antifúngica del aceite esencial de flores de Bauhinia forficata

(Link) y sus propiedades en la germinación de semillas de Cucurbita maxima (Duchesne)

\section{Resumo}

A produção agroecológica vem aumentando muito nos últimos anos, constatando a necessidade de medidas mais seguras e eficazes no controle de pragas agrícolas por meio do uso de produtos naturais como os óleos essenciais. O presente estudo teve como objetivo avaliar a composição química do óleo essencial das flores de Bauhinia forficata, sua atividade antifúngica, bem como seu efeito na germinação de sementes de Curcubita maxima. O óleo essencial foi extraído por hidrodestilação e analisados por cromatografía gasosa acoplado à espectrômetria de massas (GCEM). Posteriormente foram avaliados em diferentes concentrações quanto à atividade antifúngica sobre Sclerotinia sclerotiorum, Rhizopus microsporus e Colletotrichum gloeosporioides. No ensaio de desenvolvimento germinativo, as sementes de C. maxima foram imersas em diferentes doses de óleo essencial e comparados sua germinação e desenvolvimentos com fungicida comercial Vitavax thiram ${ }^{\circledR}$. Os compostos majoritários identificados foram guaia1(10),11-dieno (66,17\%), $\alpha$-pineno (14,06\%) e $\beta$-pineno $(4,14 \%)$. O óleo essencial das flores de $B$. forficata nas maiores concentrações inibiu o crescimento micelial dos fungos $R$. Microsporus, $C$. gloeosporioides e $S$. Sclerotiorum em $37,71 \% ; 73,7 \%$ e $25,74 \%$, respectivamente. O óleo essencial das flores de B. forficata na dose de $30 \mu \mathrm{L}$ favoreceu a germinação e o desenvolvimento das plântulas sem diferença significativa em relação ao fungicida comercial Vitavax thiram ${ }^{\circledR}$, o que implica em maior e mais saudável produção. Esses resultados indicam que o óleo essencial de $B$. forficata apresenta aspectos positivos para produções agroecológicas o que remete a grandes perspectivas evolutivas para o meio sustentável. 
Palavras-chave: Tecnologia de compostos naturais; Óleo essencial; Pata-de-vaca; Agricultura ecológica; Biocompostos.

\begin{abstract}
Agroecological production has been increasing a lot in recent years, confirming the need for safer and more effective measures to control agricultural pests through the use of natural products such as essential oils. This study aimed to evaluate the chemical composition of the essential oil of Bauhinia forficata flowers, its antifungal activity, as well as its effect on the germination of Curcubita maxima seeds. The essential oil was extracted by hydrodistillation and analyzed by gas chromatography coupled with mass spectrometry (GC-EM). They were later evaluated at different concentrations for antifungal activity against Sclerotinia sclerotiorum, Rhizopus microsporus and Colletotrichum gloeosporioides. In the germination development assay, the seeds of C. maxima were immersed in different doses of essential oil and their germination and developments were compared with commercial fungicide Vitavax thiram ${ }^{\circledR}$. The major compounds identified were guaia-1(10),11-diene (66.17\%), $\alpha$-pinene $(14.06 \%)$ and $\beta$-pinene $(4.14 \%)$. The essential oil from the flowers of B. forficata at the highest concentrations inhibited the mycelial growth of the fungi R. Microsporus, C. gloeosporioides and S. Sclerotiorum by $37.71 \%$; $73.7 \%$ and $25.74 \%$, respectively. The essential oil from $B$. forficata flowers at a dose of $30 \mu \mathrm{L}$ favored germination and seedling development without significant difference compared to the commercial fungicide Vitavax thiram ${ }^{\circledR}$, which implies greater and healthier production. These results indicate that the essential oil of B. forficata has positive aspects for agroecological production, which leads to great evolutionary perspectives for the sustainable environment.
\end{abstract}

Keyword: Natural compound technology; Essential oil; Cow leg; Ecological agriculture; Biocompounds.

\title{
Resumen
}

La producción agroecológica ha aumentado mucho en los últimos años, lo que confirma la necesidad de medidas más seguras y eficaces para controlar las plagas agrícolas mediante el uso de productos naturales como los aceites esenciales. El presente estudio tuvo como objetivo evaluar la composición química del aceite esencial de flores de Bauhinia forficata, su actividad antifúngica, así como su efecto sobre la germinación de semillas de Curcubita maxima. El aceite esencial se extrajo por hidrodestilación y se analizó mediante cromatografía de gases acoplada a espectrometría de masas (GC-EM). Posteriormente se evaluaron a diferentes concentraciones para determinar la actividad antifúngica contra Sclerotinia sclerotiorum, Rhizopus microsporus y Colletotrichum gloeosporioides. En el ensayo de desarrollo de la germinación, las semillas de C. maxima se sumergieron en diferentes dosis de aceite esencial y se comparó su germinación y desarrollo con el fungicida comercial Vitavax thiram®. Los principales compuestos identificados fueron guaia-1 (10), 11-dieno (66,17\%), $\alpha$-pineno (14,06\%) y $\beta$-pineno $(4,14 \%)$. El aceite esencial de las flores de $B$. forficata en las concentraciones más altas inhibió el crecimiento micelial de los hongos R. Microsporus, C. gloeosporioides y S. Sclerotiorum en un 37,71\%; 73,7\% y 25,74\%, respectivamente. El aceite esencial de $B$. forficata florece a dosis de $30 \mu \mathrm{L}$ favoreció la germinación y el desarrollo de las plántulas sin diferencia significativa frente al fungicida comercial Vitavax thiram ${ }^{\circledR}$, lo que implica una mayor y más saludable producción. Estos resultados indican que el aceite esencial de $B$. forficata tiene aspectos positivos para la producción agroecológica, lo que conduce a grandes perspectivas evolutivas para el medio ambiente sostenible.

Palabras clave: Tecnología de compuestos naturales; Aceite esencial; Pata-de-vaca; Agricultura ecológica; Biocompuestos.

\section{Introdução}

A produção agrícola brasileira vem aumentando sua produtividade de maneira expressiva nas últimas décadas, de modo suprir a crescente demanda de alimentos dos mercados interno e externo (IBGE 2020). Para atender a essa demanda, a quantidade de agrotóxicos utilizados nas diferentes culturas tem aumentado na mesma proporção (Jardim, Andrade \& Queiroz, 2009) com o intuito de maximizar a produção, visto que as pragas biológicas estão em constante adaptação aos elementos químicos sintéticos presentes nos defensivos agrícolas (Halfeld-Vieira et al., 2016). Assim, a cada ciclo produtivo, os agricultores têm aumentado as dosagens dos produtos utilizados ou optam pela busca de novos agrotóxicos que alcancem melhores resultados (Halfeld-Vieira et al., 2016).

A utilização de agrotóxicos com o intuito de incrementar a produtividade agrícola não é recente. A segunda guerra mundial devastou diversas áreas destinadas à produção e isso ocasionou um aumento na demanda por alimentos, elevando assim a pressão sobre a cadeia produtiva (Morais, 2009). Este cenário deu início a uma busca por produtos que viabilizassem a 
produção alimentícia em grande escala e utilização de produtos sintéticos foi a forma encontrada para aprimorar e acelerar a produção (Morais, 2009; Pinto et al., 2002).

O final da década de 1950 e início dos anos 60 foi um período de grandes mudanças na agricultura convencional, que foi posteriormente chamado de Revolução Verde (Matos \& Pessôa, 2011). Este período foi marcado por várias inovações tecnológicas com o intuito de incrementar a produção por meio do uso intensivo de insumos industriais, sementes geneticamente modificadas, mecanização (do plantio, irrigação e colheita), aprimoramento das técnicas de manejo e redução do uso de mão-de-obra (Matos, 2010).

Como resultado da Revolução Verde, nos anos subsequentes foram observados aumentos substanciais na produtividade. Entretanto, o uso indiscriminado dos agrotóxicos pode afetar o meio ambiente causando danos ecológicos e poluição ambiental, além de causar um prejuízo à saúde e humana (Lopes \& Albuquerque, 2018). Outro contraponto ao uso dos agrotóxicos é que a sua utilização pode propiciar o surgimento e proliferação de várias pragas biológicas que, com o passar do tempo, podem se adaptar aos compostos e criar resistência aos mesmos, ocasionando perdas significativas na produção (Domene et al., 2016). Isso faz com que uma quantidade cada vez maior de agrotóxicos tenha que ser utilizada para se obter os mesmos resultados e esse excesso de produtos químicos acaba intensificando os danos ambientais e à saúde humana (Lopes \& Albuquerque, 2018).

Visando a conscientização ambiental e preservação do patrimônio produtivo, iniciou-se uma busca por defensivos naturais que causassem baixo impacto no ambiente (Mazolleni \& Nogueira, 2006). Como os vegetais produzem vários metabólitos secundários, também chamados de biocompostos, como por exemplo as cumarinas, flavonoides, alcaloides e sesquiterpenos e os usam para se defender de microrganismos e fitófagos (Morais, 2009; Taiz et al., 2017; Ootanil et al., 2013), alguns pesquisadores intensificaram esforços com o intuito de testar a efetividade destes compostos no controle de diversas pragas biológicas (Mazolleni \& Nogueira, 2006; Fumagali et al., 2008; Ootanil, 2013). Adicionalmente o uso de óleos essenciais extraídos dos vegetais têm se mostrado inovadores e eficientes no controle de insetos e microrganismos (Maia, 2016), além de se mostrarem menos invasivos, pois sua toxicidade é nula ou muito baixa (Ootanil, 2013).

Os benefícios dos óleos essenciais no controle de fungos fitopatogênicos está relacionado a seu caráter lipofílico que permite a interação com a membrana celular, tornando-os mais permeáveis e causando perturbações nas estruturas celulares, extravasamento de íons e morte celular (Zhang et al., 2017). Outro fator importante, é que os óleos essenciais são mais seletivos, biodegradáveis e são formados por um conjunto de compostos, com múltiplos modos de ação e que agem em sinergismo sobre o organismo alvo, o que dificulta o desenvolvimento de resistência (Ferraz \& Freitas, 2004). Quando comparados aos produtos sintéticos, os óleos essenciais são intensamente mais viáveis principalmente quando se leva em consideração a ação de dosagem: mesmo se a quantidade de óleo essencial utilizada for superior à indicada, não ocasionará ofensa qualitativa ou nutritiva. Entretanto, se aplicarmos quantidades elevadas de agrotóxicos os mesmos podem causar contaminação ambiental e danos à saúde humana (Oliveira et al., 2018).

Diversas espécies vêm sendo estudadas quanto às atividades biológicas dos óleos essenciais por elas produzidos. Dentre os compostos naturais bioativos encontrados nos óleos essenciais, destacam-se o Eugenol extraído de Eugenia caryophyllata (Thunb.), o Carvacrol de Origanum vulgare (L.), o Timol de Lippia origanoides (Kunth.) e $\alpha$-cadinol, T-cadinol e T-muurolol extraídos da Taiwania cryptomerioides (Hayata) (Medeiros, 2014).

Uma espécie nativa da Mata Atlântica e que também é muito usada como ornamental é Bauhinia forficata Link (Lorenzi \& Souza, 2015). Esta espécie vem conquistando o interesse de muitos pesquisadores, pois apresenta propriedades medicinais, com destaque para atividades curativas e terapêuticas, além de atividade bactericida tanto em organismos Grampositivos quanto Gram-negativos (Pereira et al., 2014). Outras espécies do mesmo gênero já tiveram seus óleos estudados, como os óleos essenciais das folhas de Bauhinia pentandra (Bong.) D.Dietr. (Almeida et al., 2015) e das flores de Bauhinia 
variegata L. (Menezes Filho, 2020). A carência de estudos quanto à atividade antifúngica dos óleos essências das flores $B$. forficata justifica um estudo mais aprofundado. Portanto, o objetivou-se avaliar a composição química do óleo essencial de $B$. forficata, sua atividade antifúngica e o efeito na germinação de sementes e desenvolvimento de Curcubita máxima.

\section{Metodologia}

Este estudo trata-se de uma pesquisa experimental realizada em laboratório e casa de vegetação, buscando a confirmação quantitativa por meio da observação e analise estatística dos dados (Moresi, 2003).

\subsection{Coleta de material vegetal}

A coleta de pétalas das flores de Bauhinia forficata foi realizada na Universidade Estadual de Goiás (UEG), Unidade Universitária de Iporá - GO. As flores foram coletadas de três indivíduos de B. forficata mantidas úmidas em sacola plástica. Em seguida estas foram transportadas em um saco plástico para a trituração no laboratório Núcleo de Educação Ambiental e Pesquisa (NEAP) da UEG Unidade Universitária de Iporá-GO.

\subsection{Obtenção do óleo essencial}

Para a obtenção do óleo essencial, as pétalas das flores foram retiradas manualmente e fragmentadas em um liquidificador utilizando $1 / 2 \mathrm{~L}$ de água destilada, para 100 gramas de massa natural de flores. Posteriormente o material liquefeito foi colocado em balão destilador de fundo redondo com capacidade para $1.000 \mathrm{~mL}$ e submetido à hidrodestilação em aparelho do tipo Clevenger por um período de 3 horas.

O hidrolato resultante foi submetido à partição líquido-líquido com diclorometano para separação das fases orgânica da fase aquosa, este foi seco com sulfato de sódio anidro e evaporado em temperatura ambiente. Após a evaporação, o óleo essencial foi armazenado em refrigerador para posterior análise.

\subsection{Análise química do óleo essencial}

A composição química do óleo essencial das flores de B. forficata foi avaliada por cromatografia gasosa acoplada à espectrometria de massas (CG-EM). A análise foi realizada na Universidade Federal de São Carlos utilizando um Cromatógrafo gasoso Shimadzu GC QP 5000, equipado com uma coluna capilar de sílica fundida OPTIMA®-5-0,25 $\mu$ m (30 m x 0,25 mm) e detector por ionização por Impacto Eletrônico (IE) (70 e.V).

A temperatura inicial foi $60^{\circ} \mathrm{C}$ por $3,0 \mathrm{~min}$, seguido de um acréscimo de $3{ }^{\circ} \mathrm{C} \cdot \mathrm{min}^{-1}$ até atingir $200{ }^{\circ} \mathrm{C}$. Em seguida foi programada para um aumento de temperatura de $15^{\circ} \mathrm{C} \cdot \mathrm{min}^{-1}$ até $280^{\circ} \mathrm{C}$, permanecendo nessa temperatura por mais 1,0 min. Temperatura do injetor: $230{ }^{\circ} \mathrm{C}$, temperatura do detector: $300{ }^{\circ} \mathrm{C}$, pressão de injeção: $57,4 \mathrm{KPa}$, razão de Splitless: 150 , faixa de detecção do espectrômetro de massas: $43-550 \mathrm{~m} / \mathrm{z}$, start time (cut time do solvente): 3,0 min e fluxo de $3 \mathrm{~mL} \cdot \mathrm{min}^{-1}$. Os dados de separação foram realizados utilizando-se o Software GCMS Real Time Analysis ${ }^{\circledR}$.

A identificação dos constituintes químicos do óleo essencial das flores de B. forficata foi fundamentada nos índices de retenção linear - índice de Kovats (IK) calculado em relação ao tempo de retenção da série homóloga de n-alcanos (C-7 a C40) conforme descrito na literatura (Van Den Dool \& Kratz, 1963), e no padrão de fragmentação dos espectros de massas, por comparação com dados da literatura (Adams, 2007) e da espectroteca do National Institute of Standards and Technology (NIST 2011). 


\subsection{Ensaio antifúngico}

O ensaio foi realizado no laboratório de microbiologia agrícola do IF Goiano - Campus Rio Verde e a atividade antifúngica do óleo essencial de B. forficata foi realizada seguindo a metodologia de difusão em disco descrita por Xavier et al. (2016). Os fungos utilizados no ensaio foram Sclerotinia sclerotiorum Ss12 (BRM 29673), Rhizopus microsporus (RMT2N) e Colletotrichum gloeosporioides (CCT 5177). S. sclerotiorum foi cedido pela Embrapa Arroz e Feijão, R. microsporus pela Fundação Oswaldo Cruz - RJ e, e C. gloeosporioides pela da Fundação Andre Tosello (Campinas, SP, Brasil).

Neste experimento as placas de Petri foram previamente esterilizadas e preparadas com meio de cultura BDA (batata dextrose ágar). Após a solidificação do meio, $100 \mu \mathrm{L}$ de óleo essencial nas diferentes concentrações $(1,56 ; 3,13 ; 6,25 ; 12,5$; 25,0 e 50,0 $\mu \mathrm{L} \cdot \mathrm{mL}^{-1}$ ), diluídos em Tween $80^{\circledR}$ a $5 \%$ (v/v), foram espalhados sobre meio com auxílio de uma alça de Drigalski na superfície de toda a placa.

Posteriormente, foram depositados discos de $5 \mathrm{~mm}$ de diâmetro contendo micélio de 10 dias de idade no centro da placa. As placas foram incubadas à temperatura de $28 \pm 2^{\circ} \mathrm{C}$, e as medidas de crescimento micelial foram tomadas diariamente até o completo crescimento do fungo nas placas controle. Como controle positivo foi utilizado placas com adição de Tween $80^{\circledR}$ a $5 \%$ (v/v). O percentual de inibição de crescimento micelial (ICM) foi calculado usando a seguinte fórmula:

\section{$\operatorname{ICM}(\%)=(\underline{\text { crescimento controle }- \text { crescimento do tratamento }}) * 100$}

\section{crescimento controle}

\subsection{Ensaio fitotécnico}

\subsubsection{Tratamento das sementes}

O ensaio foi realizado no laboratório Florisvaldo Cruz sala 03 da Universidade Estadual de Goiás, Unidade Universitária de Iporá, conforme metodologia descrita por Almeida, (2012) com adequações.

Para preparo das concentrações e dos tratamentos foi realizada uma solução aquosa de Tween $80^{\circledR} 10 \%$ para ser utilizada como um "veículo" de diluição do óleo essencial e do controle, Vitavax thiram ${ }^{\circledR}$ a diluição foi em água. O tratamento usado foi baseado na proposta de Nunes, (2005), usando métodos manuais para o preparo e aplicação.

No teste das sementes de Cucurbita máxima, popularmente conhecida como abóbora moranga do Banco Ativo de Germoplasma do IF Goiano, Campus Iporá. As mesmas foram tratadas (umedecidas) com óleo essencial das flores de $B$. forficata em diferentes concentrações misturadas em solução de Tween $80^{\circledR} 10 \%$ conforme os tratamentos apresentados na Tabela 1. O experimento foi completamente casualizado em cinco tratamentos e quatro repetições, sendo usado como volume total $0,03 \mathrm{~mL} / 30 \mu 1$. Para aplicação das soluções dos respectivos produtos/doses utilizados nos tratamentos foram homogeneizadas por aproximadamente 3 minutos, e em seguida foram secas em temperatura ambiente entre $25 \pm 3^{\circ} \mathrm{C}$, por aproximadamente 24 horas sob papel filtro.

O semeio das sementes de C. maxima foi conduzido no setor de Olericultura do Instituto Federal Goiano (IF) de Iporá-GO. O ensaio foi disposto em quatro blocos casualizados, representados 4 bandejas de produção de mudas. As células das bandejas foram preenchidas com o substrato industrial BioExtrato ${ }^{\circledR}$. Após a semeadura, as bandejas foram levadas para a estufa de cultivo, onde receberam irrigações regulares (sistema de micro aspersão automatizado), permanecendo até a última avaliação. 
Tabela 1: Tratamentos empregados no ensaio fitossanitário das sementes de Cucurbita maxima com óleo essencial de Bauhinia. forficata. Iporá, Goiás, 2020

\begin{tabular}{ccccc}
\hline Tratamentos & Tween $^{8} 0^{\circledR}$ & Vitavax thiram $^{\circledR}$ & Dose de OE & Volume Total \\
\hline T0 & $100 \mu \mathrm{L}$ & - & - & $100 \mu \mathrm{L}$ \\
T1 & $70 \mu \mathrm{L}$ & $30 \mu \mathrm{L}$ & - & $100 \mu \mathrm{L}$ \\
T2 & $90 \mu \mathrm{L}$ & - & $10 \mu \mathrm{L}$ & $100 \mu \mathrm{L}$ \\
T3 & $80 \mu \mathrm{L}$ & - & $20 \mu \mathrm{L}$ & $100 \mu \mathrm{L}$ \\
T4 & $70 \mu \mathrm{L}$ & - & $30 \mu \mathrm{L}$ & $100 \mu \mathrm{L}$ \\
\hline
\end{tabular}

Fonte: Autores.

\subsubsection{Atributos biométricos e fisiológicos das plântulas de Curcubita maxima}

As características impostas para a análise fisiológica das sementes foram determinadas através de índices de velocidade da emergência, pelo teste de germinação, comprimento de plântulas, emergência final, matéria seca aérea, massa seca raiz, diâmetro do caule, largura das folhas, altura do caule, quantidade de clorofila, além da avalição da aparência física.

As avaliações foram realizadas de modo que a primeira avalição ( $4^{\circ}$ dia após o semeio) foi realizada no dia 09 de março, a segunda avaliação ( $8^{\circ}$ dia após semeio) ocorreu no dia 13 de março e a última avaliação $\left(21^{\circ}\right.$ dia após semeio) foi feita no dia 26 de março de 2020.

Índice de velocidade de emergência (I.V.E.) foi feito juntamente com o teste de emergência, a partir da contagem das sementes germinadas as quais mostraram as plântulas visíveis. Ao finalizar o teste calculou-se os dados usando a fórmula de índice de velocidade de emergência conforme Ávila et al., (2005):

\section{$\underline{\text { I.V.E. }=(\mathbf{G 1} / \mathrm{N} 1)+(\mathrm{G} 2 / \mathrm{N} 2)+\ldots+(\mathrm{Gn} / \mathrm{Nn})}$}

No qual: I.V.E. = índice de velocidade de emergência;

$\mathrm{G}$ = número de plântulas normais computadas nas contagens;

$\mathrm{N}$ = número de dias da semeadura.

Com as normas usadas para o cálculo do I.V.E., determinou-se a velocidade de emergência, calculada conforme Ávila et al. (2005) utilizando a fórmula:

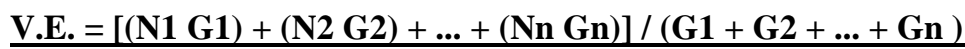

Em que: V.E. = velocidade de emergência (dias);

$\mathrm{G}=$ número de plântulas emergidas observadas em cada contagem;

$\mathrm{N}$ = número de dias da semeadura a cada contagem

Os dados foram submetidos à análise de variância (ANOVA) seguida pelo teste de Tukey, comparadas pela variação em significância de 5\% (0,05), utilizando o software $\operatorname{Sisvar}^{\circledR}$ (Ferreira, 2011).

\section{Resultados e Discussão}

\subsection{Análise química do óleo essencial}

O óleo essencial das flores de $B$. forficata apresentou aspecto translúcido e rendimento médio de $0,8 \% \pm 0,01 \%$. Em comparação com o estudo de Silva et al. (2013) que avaliaram o óleo essencial das flores de Bauhinia acuruana (Moric), os autores verificaram rendimento similar ao deste estudo com a espécie B. forficata $(0,01 \%)$, no entanto os autores identificaram compostos químicos divergentes como por exemplo: Elemene, Copaen, Elemene, cis- $\alpha$-Bergamotene, Caryophyllene, Copaene e trans- $\alpha$-Bergamotene dos que não foram identificados neste estudo. 
O cromatograma do óleo essencial das flores de B. forficata obtido nas melhores condições estabelecidas está apresentado na Figura 1. Um total de nove compostos foram identificados no óleo essencial das flores de B. forficata (Tabela 2) sendo os majoritários guaia-1(10), 11-dieno (66,17\%), $\alpha$-pineno $(14,06 \%)$ e $\beta$-pineno $(4,14 \%)$.

Figura 1: Cromatograma obtido em CG-EM/EM para o óleo essencial das flores de B. forficata.

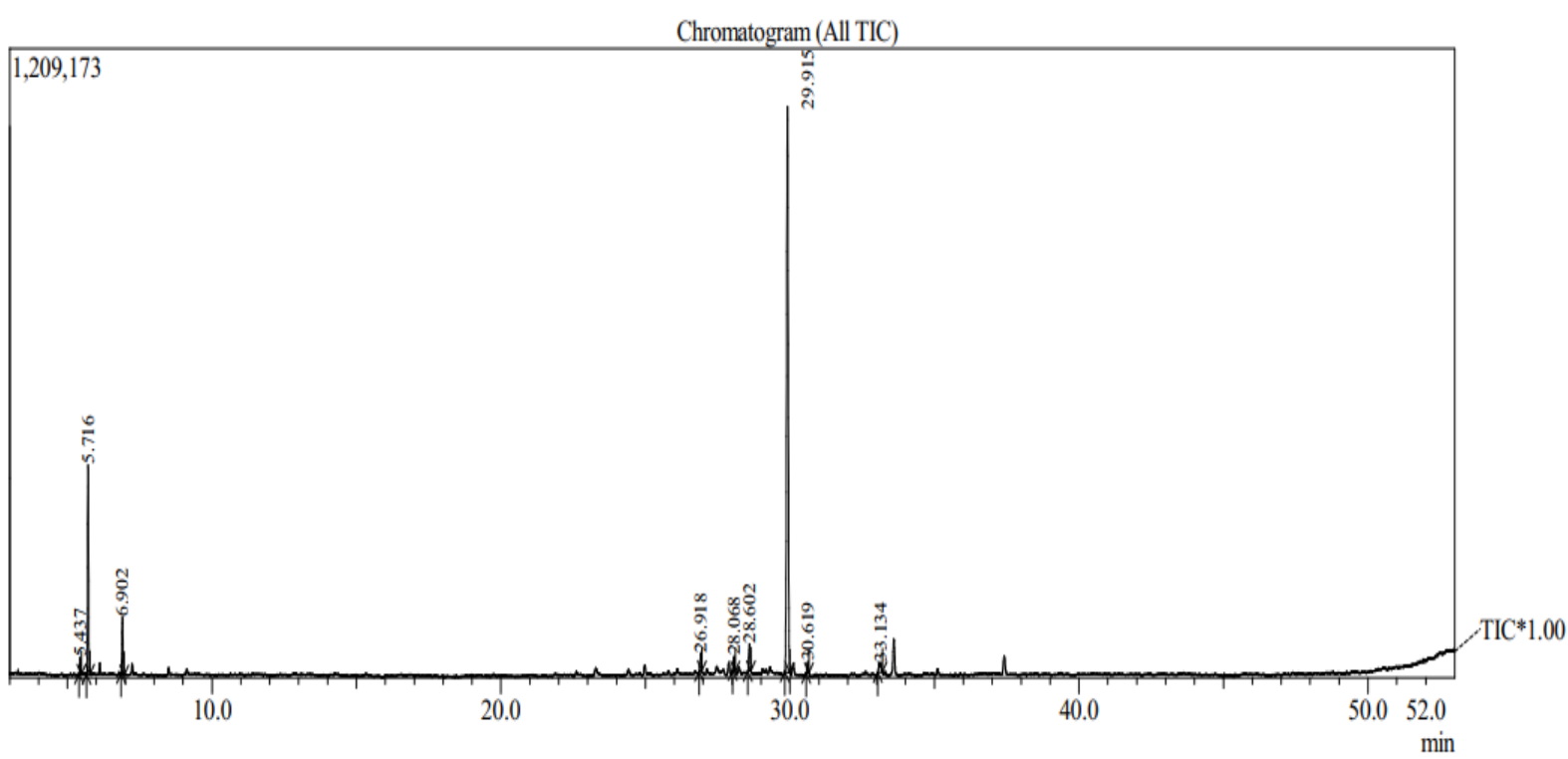

Fonte: Arquivo pessoal.

Alguns autores verificaram resultados divergentes aos encontrados neste estudo. Em comparação com o estudo de Sartolli \& Correa, (2007) os autores identificaram como compostos majoritários do óleo essencial de B. forficata o $\gamma$-elemeno (38,4\%), seguido do $\alpha$-bulneseno (17,3\%), óxido de cariofileno (9,4\%) e (Z) - $\beta$-farneseno (9,1\%); enquanto Vasudevan et al. (2013) identificaram os compostos Fitol (65.90\%), $\beta$-cariofileno (13.87\%) óxido de cariofileno (3.15\%) no óleo essencial de B. acuminata. Adicionalmente, Almeida et al., (2015) também identificaram entre os compostos majoritários semelhantes no óleo essencial de Baunhina petandra (Bong) como fitol (58,78\%) e $\beta$-cariofileno (13,64\%).

Tabela 2: Constituintes químicos do óleo essencial das flores de Bauhinia forficata.

\begin{tabular}{cccccc}
\hline Pico & TR $(\mathbf{m i n})$ & Composto & $\begin{array}{c}\text { Área }(\%) \\
\text { GC-MS }\end{array}$ & IR exp.* & IR lit.** \\
\hline 1 & 5.437 & Tricycleno & 1.08 & 924 & 921 \\
2 & 5.716 & $\alpha$-pineno & 14.06 & 934 & 932 \\
3 & 6.902 & $\beta$-pineno & 4.14 & 979 & 974 \\
4 & 26.918 & D-germacreno & 1.84 & 1484 & 1430 \\
5 & 28.068 & $\alpha$-trans-bergamotenol & 1.38 & 1514 & 1432 \\
6 & 28.602 & --cadineno & 2.82 & 1527 & - \\
7 & 29.915 & guaia-1(10),11-dieno & 66.17 & 1561 & 1601 \\
8 & 30.619 & 4-epi-cubedol & 1.02 & 1580 & 1618 \\
9 & 33.134 & tau-muurolol & 1.62 & 1647 & 1640 \\
\hline
\end{tabular}

* = índice de retenção calculado usando a equação de Van den Dool e Kratz. ** = Índice de retenção da literatura (ADAMS, 2007), baseada na equação de Van den Dool e Kratz. Fonte: Autores. 
Entretanto, os resultados deste estudo corroboram com os dados de Silva et al. (2014), que analisaram o óleo essencial das flores de B. forficata identificando 22 compostos sendo que sete desses ( $\alpha$-pineno, $\beta$-pineno, D-germacreno, trans- $\alpha$ bergamotenol, $\delta$-cadineno, guaia-1(10),11-dieno, 4-epi-cubedol, tau-muurolol) são similares aos compostos identificados neste estudo. Sousa et al., (2016) também identificaram alguns compostos similares no óleo essencial de outras espécies deste gênero como B. pulchell (Benth), com $\alpha$-pineno (23,9\%), óxido de cariofileno $(22,4 \%)$ e $\beta$-pineno $(12,2 \%)$ entre seus compostos majoritários, e no óleo essencial de B. ungulata (L.) com óxido de cariofileno (23,0\%)), (E)-cariofileno (14,5\%) e copaeno (7,2\%), entre seus compostos majoritários.

Em outro estudo, Silva et al., (2020) identificaram os compostos (E)-cariofileno (21,65\%), $\alpha$-pineno $(11,75 \%)$, espatulenol $(4,84 \%)$ e óxido de cariofileno $(4,62 \%)$ no óleo essencial das folhas frescas de Bauhinia cheilantha (Bong). Adicionalmente, no trabalho de Menezes filho, (2020), o autor identificou no óleo essencial de Bauhinia variegata L. e B. forficata os compostos germacreno, $\alpha$-pineno, $\gamma$-elemeno, silvestreno e limoneno, sugerindo que alguns destes compostos são característicos das espécies deste gênero. Vale ressaltar que as divergências entre os compostos majoritários relatados na literatura e aqueles identificados neste estudo podem ser atribuídas às diferenças nos locais de coleta, onde diferentes propriedades do solo e na sazonalidade das condições climáticas são determinantes no rendimento e composição dos óleos essenciais (Elhassan \& Ayoub, 2014).

\subsection{Atividade antifúngica}

Os resultados da atividade antifúngica do óleo essencial das flores de B. forficata estão apresentados na Figura 2. A inibição do crescimento micelial dos fungos $R$. microsporus, $C$. gloeosporioides e S. sclerotiorum para o óleo essencial das flores de B. forficata na maior concentração foi de 37,31; 73,70 e 25,74\%, respectivamente, e apresentaram resultados bastante promissores principalmente na inibição do crescimento micelial de $C$. gloeosporioides nas maiores concentrações. De acordo com o teste de Tukey não houve diferença entre as três maiores concentrações $(12,5 ; 25,0$ e 50,0 $\mu \mathrm{L} / \mathrm{mL})$ de óleo essencial de B. forficata quanto a inibição dos fungos $R$. microsporus e $C$. gloeosporioides. Quanto à inibição de $S$. sclerotiorum e $C$. gloesporioide o tratamento nas concentrações 25,0 e $12,5 \mu \mathrm{L} / \mathrm{mL}$ não diferenciam entre si, apresentando os melhores resultados. 
Figura 2: Atividade antifúngica do óleo essencial de bauhinia forficata. Médias seguidas da mesma letra, minúscula na coluna e maiúscula na linha, não diferem estatisticamente entre si pelo teste de tukey. ** significativo ao nível de $0,1 \%$ de probabilidade ( $\mathrm{p}<0,001)$; *significativo ao nível de 5\% de probabilidade $(\mathrm{p}<0,05)$; ns: não significativo $(\mathrm{p}>=0,05)$.

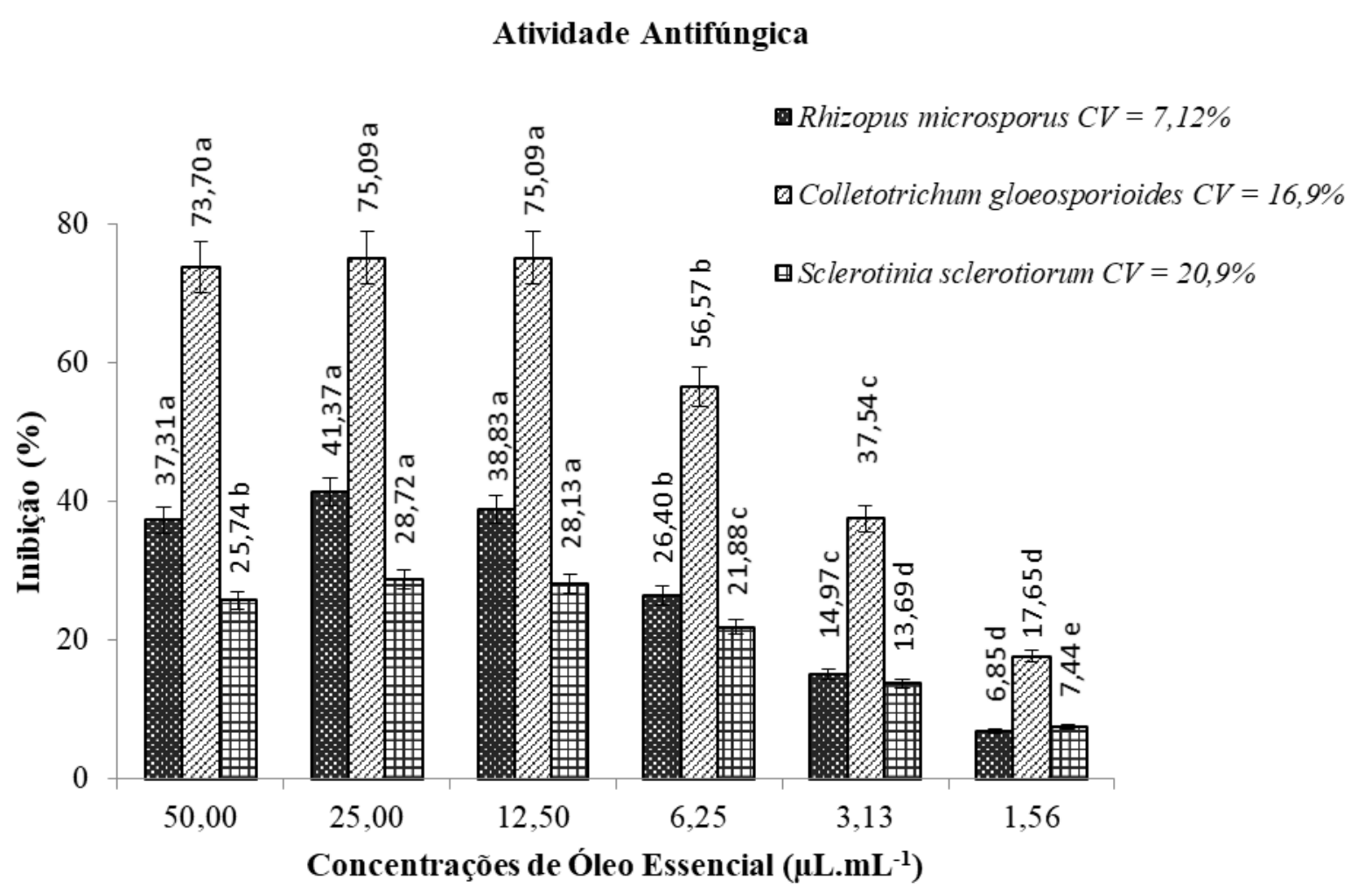

Fonte: Arquivo pessoal.

Resultados similares descritos neste trabalho também foram obtidos por Menezes Filho, (2020) que relatou uma porcentagem de inibição micelial in vitro das cepas de $S$. sclerotiorum e $C$. gloeosporioides, assim como no presente estudo, o qual apresentou grande propriedade fungicida contra os mesmos fungos. Porém, com indicativo de resistência das cepas de $C$. acutatum ao óleo essencial da flor de B. forficata, destacando a viabilidade da utilização deste óleo essencial nos fungos $S$. sclerotiorum e $C$. gloeosporioides. Os autores ainda relataram a baixa sensibilidade para $S$. sclerotiorum e C. acutatum, e alta eficiência de inibição para C. gloeosporioides por ação do óleo essencial da flor de Bauhinia variegata.

O controle antifúngico nos experimentos indicou uma nova perspectiva, no qual teve resultados promissores em portabilidade da ocorrência de atividades antifúngicas (Pereira et al., 2014). O método ecológico de produção ambientalmente consciente compreende resultados que preservem a integridade física e germinativa da semente, sem a ocorrência inibitória. $\mathrm{O}$ óleo essencial das flores de B. forficata positiva o uso na produção agroecológica, em complemento ao trabalho de Menezes Filho et al., (2020), no qual o produto testado causou inibição em S. sclerotiorum, R. microsporus e C. gloeosporioides, um dos maiores causadores de perda na produção, assim como observado no presente estudo.

O mecanismo de ação dos óleos essenciais sobre os fungos foi descrito no estudo de Park et al., (2007), com óleo de cravo e seu composto majoritário Eugenol em Trichophyton mentagrophytes. Neste estudo, os autores atribuem os resultados positivos no controle antifúngico devido ao caráter hidrofóbico de suas moléculas que interagem com as membranas celulares dos fungos, desestruturando organelas como retículo endoplasmático e mitocôndrias, além de destruir a parede celular. No estudo de Souza et al., (2010), o óleo essencial de Origanum vulgare (L) e Origanum majorana (L) causou perda de conteúdo do citoplasma caracterizado por hifas vazias, perda de pigmentação e desenvolvimento distorcido de hifas de espécies de 
Aspergillus, sugerindo que a atividade antifúngica se dá pelo ataque à parede celular, retração do citoplasma nas hifas e morte do micélio. Segundo Rana \& Rajak, (2011), o óleo essencial de cravo pode causar deformidades e distorção da estrutura dos esporos de Microsporum gypseum, além de vazamento do conteúdo celular.

Essas alterações podem estar relacionadas à interferência dos componentes do óleo essencial em reações enzimáticas de síntese da parede celular, afetando o crescimento e morfogênese fúngica (Carmo et al., 2008). Adicionalmente, Tian et al., (2012) verificaram que o mecanismo de ação do óleo essencial de Anethum graveolens (L.) alterou a permeabilidade da membrana plasmática em Aspergillus flavus e provocou acúmulo de espécies reativas de oxigênio induzido por disfunção mitocondrial.

Os compostos majoritários dos óleos essenciais também têm sido estudados quanto ao seu mecanismo de ação sobre fungos fitopatogênicos. A exemplo, Chavan \& Santosh, (2014) verificaram deterioração da membrana plasmática de leveduras do vinho sob efeito do Timol e Carvacrol. De modo similar, Gao et al., (2016) observaram que a exposição de Fusarium graminacearum ao Timol resultou em inibição da produção de conídios, do crescimento de hifas, induziu a peroxidação lipídica e a interrupção da biossíntese do ergosterol (essenciais para a estrutura da membrana plasmática).

No estudo de Zhang et al., (2018), os autores avaliaram o efeito do Timol sobre a transcriptoma do RNA-Seq de fungos do gênero Fusarium e verificaram uma depleção dos genes dos fungos relacionados ao metabolismo de glicoesfingolipídios e esfingolipídios, enquanto os genes envolvidos em uma atividade antioxidante, biossíntese de quitina e modificação da parede celular foram regulados positivamente.

Os constituintes químicos extraídos de maior concentração nos óleos essenciais das flores de B. forficata foram guaia-1(10),11-dieno (66,17\%), $\alpha$-pineno (14,06\%) e $\beta$-pineno (4,14\%). Além disso, a inibição do crescimento micelial contra o fungo $C$. gloeosporioides ocorreu de forma significativa a partir da concentração de $12,5 \mu \mathrm{L} / \mathrm{mL}^{-1}$ de óleo essencial de flores de B. forficata. Entretanto, o óleo das flores de B. forficata não possui efeito fungicida significativo para os fungos $S$. sclerotiorum e $R$. microsporus. Portanto, esses dados confirmam que provavelmente o óleo essencial e seus componentes químicos atuam sobre a parede celular dos fungos, suas membranas celulares, aumentando a produção de espécies reativas de oxigênio na superfície celular fúngica, bem como bloqueando os genes moleculares fúngicos necessários para a formação da parede celular e síntese da membrana plasmática. Entretanto, não foram encontrados na literatura registros de estudos com os compostos majoritários identificados no óleo essencial de B. forficata sobre o mecanismo de ação dos fungos.

\subsection{Germinação e emergência de Cucurbita maxima}

Não há diferenças entre os tratamentos avaliados para os parâmetros de germinação no $4^{\circ}, 8^{\circ}$ e $21^{\circ}$ dia, bem como para IVE e VE (Tabela 3).

O índice de velocidade de emergência, bem como a velocidade de emergência dos tratamentos não apresentou diferença entre os tratamentos com óleo essencial, controle e Vitavax thiram ${ }^{\circledR}$ (Tabela 3). Isso implica que óleo essencial e o solvente utilizado não apresentam incompatibilidade e ou prejuízo a germinação e emergência quando comparado ao controle químico e controle (água), assim posicionando como opção a produção agroecológica. 
Tabela 3: Porcentagem de sementes germinadas de Curcubita maxima por tratamento no $4^{\circ}, 8^{\circ}$ e $21^{\circ}$ dia após a semeadura.

\begin{tabular}{|c|c|c|c|c|c|c|}
\hline \multirow{2}{*}{$\begin{array}{l}\text { Avaliação da } \\
\text { Germinação }\end{array}$} & \multicolumn{5}{|c|}{ Tratamentos } & \multirow{2}{*}{$\begin{array}{c}\text { Resultados da Anova } \\
(\mathbf{G L}=\mathbf{4})\end{array}$} \\
\hline & (T0) & (T1) & (T2) & (T3) & (T4) & \\
\hline $4^{\circ}$ dia & 28,70 & 44,44 & 22,22 & 15,74 & 24,07 & $\mathrm{~F}=2.758 ; \mathrm{p}=0.0669 \mathrm{~ns}$ \\
\hline $8^{\circ}$ dia & 95,37 & 94,44 & 98,14 & 94,44 & 100,00 & $\mathrm{~F}=1.366 ; \mathrm{p}=0.2921 \mathrm{~ns}$ \\
\hline $21^{\circ}$ dia & 94,44 & 95,37 & 100,00 & 95,37 & 100,00 & $\mathrm{~F}=0.894 ; \mathrm{p}=0.4917 \mathrm{~ns}$ \\
\hline (IVE) & 23,59 & 27,46 & 22,58 & 20,28 & 23,28 & $\mathrm{~F}=2.326 ; \mathrm{p}=0.1037 \mathrm{~ns}$ \\
\hline (VE) & 13,12 & 12,56 & 13,51 & 13,73 & 13,39 & $\mathrm{~F}=2.764 ; \mathrm{p}=0.0665 \mathrm{~ns}$ \\
\hline
\end{tabular}

IVE: Índice de Velocidade de Emergência; VE: Velocidade de Emergência. ns: não significativo (P $\leq 0,05)$. Fonte: Autores.

Os dados na literatura quanto ao uso dos óleos essenciais na germinação de sementes são distintos. Bernardo et al., (1998), avaliaram a atividade antifúngica do óleo essencial de manjericão, carqueja e arruda, e seu potencial como estimulante germinativo. Os autores destacaram que ocorreu inibição no fator germinativo, com isso ocasionando um atraso no período de desenvolvimento evolutivo dos folhetos primordiais e eventualmente no crescimento da planta, impedindo também o crescimento micelial de Colletotrichum graminicola. Nascimento, (2017) também verificou que o óleo essencial de citronela ocasionou uma redução no fator germinativo das sementes de pimentão, resultados divergentes dos determinados neste trabalho com B. forficata sobre a germinação das sementes de C. maxima.

Segundo El-Awady, (2019), fatores como dose, espécie testada, concentração e componentes químicos dos óleos essenciais influenciam nos efeitos aleloquímicos induzindo estimuladores ou inibindo a germinação das sementes e outros processos fisiológicos. Em baixas doses, o óleo essencial de tomilho melhorou a germinação das sementes de brócolis (Leth, 2002). Por outro lado, os óleos essenciais de copaíba e manjericão não afetaram a qualidade fisiológica das sementes de feijão fava em comparação com o controle e o fungicida Captan ${ }^{\circledR}$, além de reduzir consideravelmente o percentual de incidência dos fungos associados às sementes de feijão-fava (Gomes et al., 2016). Adicionalmente, as sementes de soja (Glycine max L.) tratadas com óleo essencial de Cymbopogon flexuosus, Eucalyptus globulus e Baccharis trimera apresentaram os mesmos percentuais de germinação daquelas tratadas com o fungicida Vitavax thiram ${ }^{\circledR}$ ou da testemunha (Daronco, 2013).

Os efeitos dos óleos essenciais sobre a germinação de sementes podem estar relacionados com sua composição química. No estudo reportado por Vokou et al., (2003), os autores avaliaram o efeito de 47 compostos químicos de óleos essenciais, dos quais 24 aumentaram a germinação de sementes de Lactuca sativa, entre eles o $\alpha$-pineno e $\beta$-pineno, compostos presentes no óleo essencial de B. forficata. Neste estudo, o óleo essencial de B. forficata não apresentou fitotoxicidade sobre as sementes de C. maxima.

\subsection{Biometria e fisiologia das plântulas de Cucurbita maxima}

Não houve diferença significativa entre os tratamentos quanto aos atributos biométricos de massa seca das raízes, relação aérea/raíz, área foliar/planta, clorofila A, clorofila B e clorofila total (Tabela 4). Assim, não há efeitos fisiológicos detectáveis nos parâmetros de clorofila avaliados.

De acordo com o autor Pes \& Arenhard, (2015) o crescimento vegetal pode ser conceituado como um acréscimo que ocorre na massa seca, a qual é irreversível, e para esse tal acontecimento é preciso que a planta respire bem, estabelecendo superioridade a sua taxa de fotossíntese. Neste sentido, observa-se que somente na menor dose de óleo essencial houve 
comportamento inferior ao controle químico. Portanto, doses maiores (T3 e T4) foram capazes de proporcionar produtividade de massa seca da parte aérea, massa seca total, diâmetro do coleto igualmente aos controles.

Há necessidade de estudos destinados a elucidar a hipótese de que o solvente possa exercer efeito negativo, pois nas doses maiores, onde a proporção de solvente é menor não há prejuízo nos atributos biométricos e fisiológicos estudados.

Tabela 4: Atributos biométricos e fisiológicos das plântulas de Curcubita maxima aos 21 dias provenientes das sementes tratadas diferentes doses de óleo essencial de B. forficata, Vitavax Thiram e Controle.

\begin{tabular}{lccccc} 
& \multicolumn{5}{c}{ Tratamentos } \\
\hline Variável/médias & T0 & T1 & T2 & T3 & T4 \\
\hline Massa Seca Raízes / planta (g) & $0,105 \mathrm{a}$ & $0,090 \mathrm{a}$ & $0,065 \mathrm{a}$ & $0,060 \mathrm{a}$ & $0,065 \mathrm{a}$ \\
Massa Seca Aérea / planta (g) & $0,450 \mathrm{ab}$ & $0,532 \mathrm{~b}$ & $0,420 \mathrm{a}$ & $0,452 \mathrm{ab}$ & $0,477 \mathrm{ab}$ \\
Massa Seca Total / Planta (g) & $0,555 \mathrm{ab}$ & $0,622 \mathrm{~b}$ & $0,485 \mathrm{a}$ & $0,512 \mathrm{ab}$ & $0,542 \mathrm{ab}$ \\
Relação Aérea / Raiz (mm) & $5,30 \mathrm{a}$ & $6,00 \mathrm{a}$ & $6,66 \mathrm{a}$ & $7,37 \mathrm{a}$ & $7,44 \mathrm{a}$ \\
Diâmetro Coleto (mm) & $4,67 \mathrm{ab}$ & $4,86 \mathrm{~b}$ & $4,26 \mathrm{a}$ & $4,51 \mathrm{ab}$ & $4,46 \mathrm{ab}$ \\
Altura (cm) & $18,38 \mathrm{bc}$ & $15,77 \mathrm{ab}$ & $18,46 \mathrm{c}$ & $18,14 \mathrm{bc}$ & $14,02 \mathrm{a}$ \\
Largura das Folhas (cm) & $4,49 \mathrm{ab}$ & $4,96 \mathrm{~b}$ & $4,25 \mathrm{ab}$ & $4,26 \mathrm{ab}$ & $4,15 \mathrm{a}$ \\
Área Foliar / Planta (cm) & $62,77 \mathrm{a}$ & $66,00 \mathrm{a}$ & $61,00 \mathrm{a}$ & $63,03 \mathrm{a}$ & $59,47 \mathrm{a}$ \\
Clorofila A (\%) & $269,55 \mathrm{a}$ & $298,85 \mathrm{a}$ & $279,80 \mathrm{a}$ & $279,25 \mathrm{a}$ & $279,00 \mathrm{a}$ \\
Clorofila B (\%) & $65,05 \mathrm{a}$ & $73,90 \mathrm{a}$ & $65,30 \mathrm{a}$ & $65,95 \mathrm{a}$ & $74,00 \mathrm{a}$ \\
Clorofila Total (\%) & $334,60 \mathrm{a}$ & $370,75 \mathrm{a}$ & $345,10 \mathrm{a}$ & $345,20 \mathrm{a}$ & $353,00 \mathrm{a}$ \\
\hline
\end{tabular}

Letras diferentes na linha representa diferença significativa pelo teste Tukey $(0,05)$. Fonte: Autores.

Segundo Moreira, (2004) os sistemas radiculares avantajados condizem com um grande fluxo consumista de carbono e de absorção de Fósforo (P), o que compreende uma necessidade de grande quantidade de raízes para o suprimento e beneficiamento foliar, e assim consequentemente abranger uma melhor absorção dos raios solar e maior transformação em energia e absorção nutricional.

Os óleos essenciais são uma das melhores alternativas agronômica e ecologicamente sustentável na relação produção e qualidade de vida humana (Daronco, 2013). Conforme observado no presente estudo, o óleo essencial de B. forficata apresentou efeito fungicida promissor sobre o fungo C. gloeosporioides causador de antracnoses em Cucurbitáceas e, apresentaram resultados similares ao tratamento com fungicida sintético Vitavax thiram ${ }^{\circledR}$ durante a avaliação dos atributos fisiológicos das plântulas, sendo uma alternativa de uso sustentável na produção agrícola de C. maxima, além de reduzir os impactos ambientais causados pelos produtos sintéticos.

\subsubsection{Estimativas quantitativas}

Houve comportamento linear crescente na relação parte Aérea:Raiz conforme aumenta as doses de óleo essencial, embora o comportamento quadrático apresente tendencia de redução na altura (Figura 3A e 3B).

Para massa seca total (Figura 3C) houve regressão quadrática, nota-se que a menor dose, que por consequência apresentou a maior proporção do solvente na mistura utilizada para tratamento das sementes de C. maxima é responsável pela redução neste atributo biométrico importante na produção de plântulas (Mudas) da espécie estudada, reforçando a hipótese anteriormente levantada. Este comportamento demonstra que quanto menor a proporção de solvente e maior a de óleo essencial, melhor é o desempenho das plântulas aos 21 dias após o semeio. 
O Comportamento da clorofila B foi de aumento crescente conforme o aumento nas doses de óleo essencial (Figura 3D). Este comportamento pode ser consequência do sombreamento proporcionado pelo ganho em altura das plântulas nesta fase de desenvolvimento. O sombreamento de plantas provoca este comportamento fisiológico (Rego \& Possamai, 2006).

Figura 3: Regressões ajustadas para as doses de óleo essencial sobre a relação a parte aérea e raiz (A), altura da planta aos 21 dias (B), massa seca total (C) e clorofila B (D).
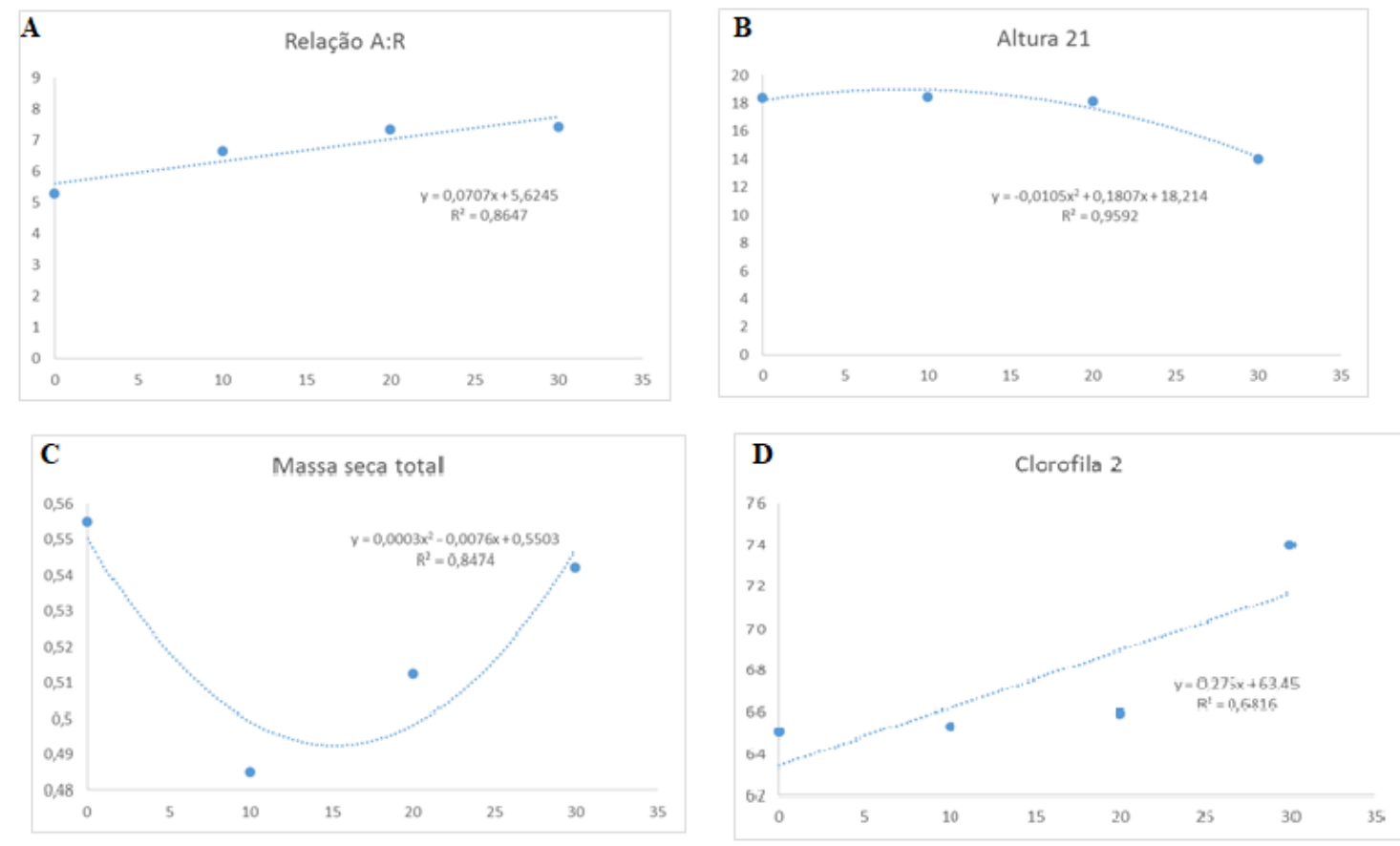

Fonte: Arquivo pessoal.

Portanto, o presente estudo demonstrou que as dosagens utilizadas de óleo essencial de $B$. forficata não causaram nem um tipo de atraso na germinação das sementes de $C$. maxima e no desenvolvimento das plantas. A indicação da concentração do óleo essencial é de grande influência, visto que a utilização deste produto mostrou eficiência contra fitopatógenos e favorece o desenvolvimento vegetal.

\section{Conclusão}

Conclui-se que, o óleo essencial de flores de B. forficata apresentou efeito fungicida promissor sobre o fungo $C$. gloeosporioides causador de antracnoses em cucurbitáceas. Com isso pode atuar como um fungicida natural sem causar prejuízo ao desenvolvimento da planta de C. maxima. Desse modo, pode-se concluir que o uso do óleo essencial de B. forticata pode ser uma alternativa de uso sustentável na produção de $C$. maxima. Adicionalmente, são necessárias futuras pesquisas para otimização dos resultados, utilizando a análise integrada entre as sementes de $C$. maxima infectada com o fungo $C$. gloeosporioides e o óleo essencial das flores de B. forticata sob diferentes concentrações ao longo do processo de germinação.

\section{Agradecimentos}

Os autores agradecem à Universidade Estadual de Goiás (UEG), ao Instituto Federal de Educação, Ciência e Tecnologia Goiano (IF Goiano), ao Instituto Federal de Educação, Ciência e Tecnologia de Barbacena e à Universidade Federal de São Carlos (UFSCAR) pelo apoio; e aos órgãos de fomento em pesquisa CAPES, CNPq, FINEP. 


\section{Referências}

Adams R. P. (2007). Identification of essential oil components by gas chromatography/quadrupole mass spectroscopy. 4. ed. Carol Stream: Allured Publishing Corporation, 804 .

Almeida M. C. S., Souza L. G. S., Ferreira D. A., Monte F. J. Q., Braz-Filho R., \& Lemo T. L. G. S. (2015). Chemical composition of the essential oil and fixed oil Bauhinia pentandra (Bong.) D. Dietr. Original Article, 11, 362-364.

Almeida A. S. Villela F. A., Meneghello G. E., Lauxen L. R., \& Deuner C. 2012. Desempenho fisiológico de sementes de aveia-preta tratadas com tiametoxam. Semina: Ciências Agrárias, 33(5), 1619-1628.

Ávila M. R., Braccini A. L. E., Scapim C. A., Martorelli D. T., \& Albrecht L. O. P. (2005). Testes de laboratório em sementes de canolae a correlação com a emergência das plântulas em campo. Revista Brasileira de Sementes, 27(1), 62-70.

Bernardo R., Schwan-Estrada K. R. F., Stangarlin J. R., Cruz M. E. S., \& Pascholati, S. F. (1998). Fungitoxidade de alguns óleos essenciais contra fungos fitopatogênicos. Fitopatologia Brasileira, 23, 227.

Carmo E. S., Lima E. O., \& Souza E. O. (2008). The potential of Origanum vulgare l. (Lamiaceae) essential oil in inhibiting the growth of some food-related Aspergillus species. Brazilian Journal Microbiology, 39, 362-367.

Chavan P. S, \& Santosh G. T. (2014). Antifungal activity and mechanism of action of carvacrol and thymol against vineyard and wine spoilage yeast. Food Control. 6, 115-120.

Daronco M. V. (2013). Óleos essenciais no tratamento de sementes de soja (Glycine max L.) https://bibliodigital.unijui.edu.br:8443/xmlui/bitstream/handle/123456789/1790/TCC\%20FINAL\%20MAICON.pdf?sequence=1.

Domene M. P., Glória E. M., Biagi J. D., \& Benedetti L. M. (2016). Efeito do tratamento com óleos essenciais sobre a qualidade fisiológica e sanitária das sementes de milho (Zea mays). Arq. Inst. Biol., 83, 2016.

El-Awady A. A. E. F. (2014). Efeito dos óleos essenciais na capacidade de armazenamento e preservação de algumas culturas vegetais. IntechOpen, 87213.

Elhassan I. A., \& Ayoub, S. M. H. (2014). Effect of Geographical location on essential oil Content and Composition of Xylopia aethiopica. American Journal of Research Communication, 2(1).

Ferraz S., \& Freitas L.G. (2004). O controle de fitonematóides por plantas antagonistas e produtos naturais. LPPO Agroecologia.

Ferreira D. F. (2011). Sisvar: a computer statistical analysis system. Ciência Agrotecnol. 35(6), 1039-1042.

Fumagali E., Gonçalves R. A. C., Machado M. F. P. S., Vidoti G. J., \& Oliveira A. J. B. (2008). Produção de metabólitos secundários em cultura de células e tecidos de plantas: o exemplo dos gêneros Tabernaemontana e Aspidosperma. Rev. bras. farmacogn. 18, 4.

Gao T., Zhou H., Zhou W., Hu L., Chen J., \& Shi Z. (2016). The Fungicidal Activity of Thymol against Fusarium graminearum via Inducing Lipid Peroxidation and Disrupting Ergosterol Biosynthesis. Molecules. 18, 21(6), 770.

Gomes R. S. S., Nunes M. C., Nascimento L. C., Souza J. O., \& Porcino M. M. (2016). Eficiência de óleos essenciais na qualidade sanitária e fisiológica em sementes de feijão-fava (Phaseolus lunatus L.). Rev. Bras. Pl. Med., 18(1), 279-287.

Halfeld-Vieira Marinho-Prado, J. S. Nechet, K. De L. Morandi, M. A. B. \& Bettiol, W. (2016). Defensivos Agrícolas Naturais: Uso e Perspectivas. Embrapa, Brasília, 853 .

Jardim I. C. S. F., Andrade J. A., \& Queiroz S. C. N. (2009). Resíduos de agrotóxicos em alimentos: uma preocupação ambiental global - um enfoque às maçãs. Química Nova, 32(4), 996-1012.

Leth V. (2002). Use of essential oils as seed treatment. IPGRI Newsletter. 9, 15-16.

Lopes C. V. A., \& Albuquerque G. S. C. A. (2018). Agrotóxicos e seus impactos na saúde humana e ambiental: uma revisão sistemática. Revista Saúde e Debate, 42(117), 518-534.

Lorenzi H., \& Souza H. M. (2015). Plantas ornamentais no Brasil: arbustivas, herbáceas e trepadeiras. (2a ed.), Instituto Plantarum de Estudos da Flora Ltda., 1, 120.

Maia T. F., Donato A., \& Fraga M. E. (2016). Atividade antifúngica de óleos essenciais de plantas. Revista Brasileira de Produtos Agroindustriais, 17(1), 105116.

Matos A. K. V. (2010). Revolução Verde, Biotecnologia e Tecnologias Alternativas. Cadernos da FUCAMP, 10(12), 1-17.

Matos P. F., \& Pessoa V. L. S. (2011). A Modernização da Agricultura no Brasil e os Novos Usos do Território. Geo UERJ, 22(2), $290-322$.

Mazoleni E. M., Nogueirai J. M. (2006). Agricultura orgânica: características básicas do seu produtor. Rev. Econ. Sociol. Rural, 44, 2.

Medeiros F. C. M. (2014). Caracterização química e atividade biológica de óleos essenciais de plantas do Cerrado contra fungos xilófagos. Dissertação de Mestrado. Publicação PPGEFL.DM-238/2014. Departamento de Engenharia Florestal. Universidade de Brasília, Brasília DF.

Menezes Filho, A. C. P. (2020). Physicochemical evaluation and antioxidant and antifungal activities of essential oils from Bauhinia forficata Link. and Bauhinia variegata L. flowers. Rev. de Agroec. no Semiárido (RAS), 4(1), 1 - 11. 
Menezes-Filho A. C. P., Santos D. B., Nascimento R. C., Oliveira M. S., \& Castro C. F. S. (2020). Evolution and antifungo, antifungo of essential oil from Bauhinia forficate flower Link (Fabaceae). Revista de Agricultura Neotropical, 7(2), 57-61.

Moresi E. (2003). Metodologia da pesquisa. Universidade Católica de Brasília - UCB, Brasília DF.

Nascimento D. M. (2017). Efeito do tratamento de sementes de pimentão com óleos essenciais sobre o controle de Colletotrichum gloeosporioides e o potencial fisiológico das sementes. Dissertação de mestrado em Ciências Agronômicas pela Universidade Estadual Paulista Júlio de Mesquita Filho, Botucatu.

Nunes J. C. (2005). Tratamento de semente: qualidade e fatores que podem afetar a sua performance em laboratório. São Paulo: Syngenta Proteção de Cultivos Ltda.

Oliveira J. L. S., Lima A. C. B., Minini D. E., \& Silva E. (2018). Usos, efeitos e potencial tóxico dos agrotóxicos na qualidade do solo. Agrarian Academy, Centro Científico Conhecer, 5(9), 454.

Ootanil M. A., Aguiar R. W. S., Ramos A. C. C., Brito D. R., Silva J. B., \& Cajazeira J. P. (2013). Utilização de Óleos Essenciais na Agricultura. Journal of Biotechnology and Biodiversity, 4(2), 162-174.

Park M. J., Gwak K. S., Yang I., Choi W. S. J. O., Chang J. W., Jeung E. B., \& Choi I. G. (2007). Atividades antifúngicas dos óleos essenciais em Syzygium aromaticum (L.) Merr. Et Perry e Leptospermum petersonii Bailey e seus constituintes contra vários dermatófitos. The J. Microbiol., 45, 460-465.

Pereira A. C. S., Ribeiro G. E. I., Souza L. C. R. I., Rufino L. R. A. I., Cabral I. S. R. I., Boriollo M. F. G. I., Nogueira D. A. I., Oliveira N. M. S. I., \& Fiorini J. E. I. (2014). Atividade biológica do extrato hidroalcoólico de Bauhinia forficata Link sobre Herpetomonas samuelpessoai (Galvão.) Roitman. Rev. bras. plantas med., 16(3).

Pinto A. C., Silva D. H. S., Bolzani V. S., Lopes N. P., \& Epifanio R.A. (2002). Produtos Naturais: Atualidade, Desafios e Perspectivas. Quím. Nova, 25(11).

Rana I. S., Rana A. S., \& Rajak R. C. (2011). Evaluation of antifungal activity in essential oil of the Syzygium aromaticum (L.) by extraction, purification and analysis of its main component eugenol. Brazilian Journal of Microbiology, 42(4), 1269-1277.

Rego G. M., \& Possamai E. (2006). Efeitos do sombreamento sobre o teor de clorofila e crescimento inicial do Jequitibá-rosa. Revista Florestal Brasileira, 53, 179-194.

Sartolli P., \& Correa D. S. (2007). Constituents of Essential Oil from Bauhinia forficate Link. Journal of Essential Oil Research, 19 (5), 468 - 469.

Silva B. P. C., Albuquerque B. N. L., Rocha S. K. L., \& Navarro D. M. A. F. (2014). Voláteis das flores de pata-de-vaca (Bauhinia forficata link) por três métodos: headspace, hidrodestilação e fluido supercrítico. $54^{\circ}$ Congresso Brasileiro de Química.

Silva G. R. W., Sousa 1. M., Lemos T. L. G., Arriaga A. M. C., Andrade-Neto M., Santiego G. M. P., Ferreira Y. S., Alves P. B. A. E., \& Jesus H. C. R. (2011). Chemical Composition and Larvicidal Effects of Essential Oil from Bauhinia acuruana (Moric) against Aedes aegypti. Florida State University, 23.

Silva A. M. A., Silva H. C., Monteiro A. O., Lemos T. L. G., Souza S. M., Militão G. C. G., Santos H. V., Alves P. B., Romero N. R., \& Santiago G. M. P. (2020). Chemical composition, larvicidal and cytotoxic activities of the leaf essential oil of Bauhinia cheilantha (Bong.) Steud, South African Journal of Botany, 131, $369-373$.

Sousa L. M., Carvalho J. L., Gois R. W. S., Silva H. C., Santiago G. M. P., Lemos T. L. G., Arriaga A. M. C., Alves P. B., Matos I. L., Militão G. C. G., Silva P. B. N., \& Silva T. G. (2016). Chemical Composition, Larvicidal and Cytotoxic Activities of the Essential Oils from two Bauhinia Species. Records of Natural Products, 10 (3), 341-348.

Souza N. A. B., Lima E. O., Guedes D. N., Pereira F. O., Souza E. L., \& Sousa F. B. (2010). Efficacy of Origanum essential oils for inhibition of potentially pathogenic fungi. Brazilian Journal of Pharmaceutical Sciences, 46(3).

Taiz L., Zeiger E., Moller I., \& Murphy, A. (2017). Fisiologia e desenvolvimento vegetal. (6a ed.), Artmed, 888.

Tian J., Ban X., Zeng H., He J., Chen Y., \& Wang Y. (2012). O mecanismo de ação antifúngica do óleo essencial de endro (Anethum graveolens L.) em Aspergillus flavus. PLoS ONE 7 (1): e30147.

Van Den Dool H., \& Dec Kratz P. (1963). A generalization of the retention index system including linear temperature programmed gas-liquid partition chromatography. Journal Chromatography. A 11, 463-471.

Vasudevan V., Mathew J., \& Baby S. (2013). Chemical Composition of Essential Oil of Bauhinia acuminata Leaves. Asian Journal of Chemistry, 25, (4), 2329-2330.

Vokou D., Douvli P., Blionis G. J., \& Halley J. M. (2003). Effects of monoterpenoids, acting alone or in pairs, on seed germination and subsequent seedling growth. Journal of Chemical Ecololgy. 29: 2281-2301.

Xavier M. N., Alves J. M., Carneiro N. S., Souchie E. L., Silva E. A. J., Martins C. H. G., Ambrósio M. A. L. V., Egea M. B., Alves C. C. F., \& Miranda M. L. D. (2016). Composição química do óleo essencial de Cardiopetalum calophyllum Schltdl. (Annonaceae) e suas atividades antioxidante, antibacteriana e antifúngica. Revista Virtual de Química, 8, 5.

Zhang M., Ge J., \& Yu X. (2018). Transcriptome Analysis Reveals the Mechanism of Fungicidal of Thymol Against Fusarium oxysporum f. sp. niveum. Current Microbiology. 75(4): 410-419.

Zhang J., Ye K., Zhang X., Pan D., Sun Y., \& Cao J. (2017). Antibacterial Activity and Mechanism of Action of Black Pepper Essential Oil on Meat-Borne Escherichia coli. Frontiers in Microbiology, 7: 2094. 